\title{
Characterization of Wheel Surface Topography in cBN Grinding*
}

\author{
Masakazu FUJIMOTO**, Yoshio ICHIDA***, Ryunosuke SATO*** and Yoshitaka MORIMOTO***
}

The wheel surface topography in the grinding process with vitrified $\mathrm{cBN}$ wheels has been investigated on the basis of 3-dimensional analysis using a multi-probe SEM, and the relationships between these results and the grinding characteristic parameters have been discussed. Moreover, the change of the wheel surface profile in the grinding process has been evaluated using fractal analysis. There are two regions: an initial wear region and a steadystate wear region, in the grinding process. In the initial wear region, a rapid decrease of grinding force and a rapid increase of wheel wear occur with increasing stock removal. In the steady-state wear region, the micro self-sharpening phenomenon owing to the micro fracture as well as the attritious wear of cutting edge occurs. The change in fractal dimension of the wheel surface is closely related to the change of grinding force dominated by the wear behavior of grain cutting edges.

Key Words: Grinding, Grinding Force, Surface Grinding, Vitrified cBN Grinding Wheel, Wheel Surface Topography, Fractal Dimension, Grain Cutting Edge Density, Micro Self-Sharpening Phenomenon

\section{Introduction}

cBN abrasive grains have very stable thermal and chemical properties as well as a hardness next to diamond, so that the cutting edge is rarely worn by cohesion or chemical wear during the grinding process and can grind easily hard materials such as high speed tool steels. The demand for the higher performance of $\mathrm{cBN}$ wheels is increasing, as they are becoming widely used for precision grinding of various difficult-to-grind materials. In order to enhance the grinding performance of $\mathrm{cBN}$ wheels, it is essential to characterize the topography of wheel surface in the grinding process over the wheel life ${ }^{(1)-(3)}$.

In this study, the changes of the wheel surface topography such as shapes and distributions of the grain cutting edges and so on in the grinding process with vitrified cBN wheels are investigated on the basis of 3-dimensional analysis using a multi-probe SEM, and the relationships between these results and the grinding characteristic parameters are discussed. In addition, the change of the wheel

* Received 18th October, 2005 (No. 05-4214)

** Graduate School of Engineering, Utsunomiya University, 7-1-2 Yoto, Utsunomiya 321-8585, Japan

*** Department of Mechanical Systems Engineering, Utsunomiya University, 7-1-2 Yoto, Utsunomiya 321-8585, Japan. E-mail: ichida@cc.utsunomiya-u.ac.jp surface profile in the grinding process is evaluated using fractal analysis.

\section{Experimental Procedure}

Figure 1 shows the schematic illustration of the experimental set up. In this study, we have used a vitrified $\mathrm{cBN}$ wheel with a replaceable $\mathrm{cBN}$ insert in order

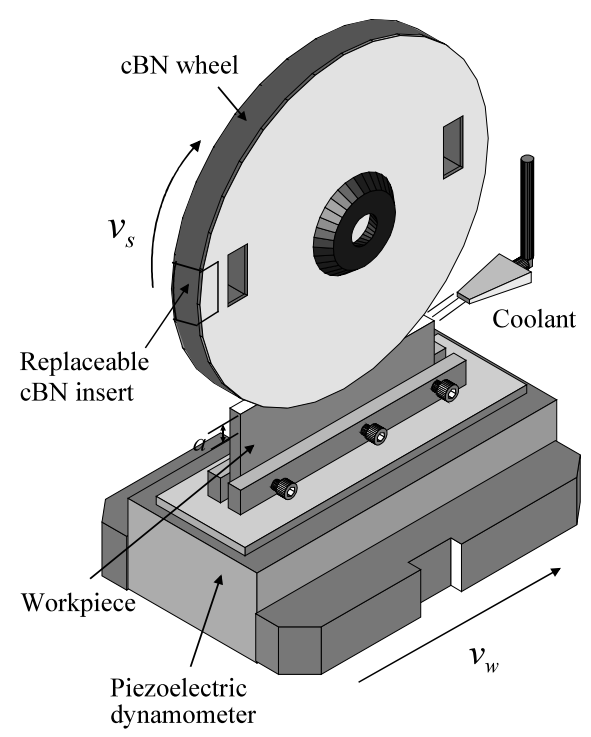

Fig. 1 Schematic illustration of experimental setup 
Table 1 Experimental conditions

\begin{tabular}{l|l}
\hline Grinding method & Surface plunge grinding, Up-cut \\
\hline Grinding wheel & $\begin{array}{l}\text { cBN80L100V } \\
\text { Dimensions: } \phi 200 \times t 10 \mathrm{~mm}\end{array}$ \\
\hline Peripheral wheel speed $v_{s}$ & $33 \mathrm{~m} / \mathrm{s}$ \\
\hline Work speed $\quad v_{w}$ & $0.15 \mathrm{~m} / \mathrm{s}$ \\
\hline Wheel depth of cut $\quad a$ & $10 \mu \mathrm{m}$ \\
\hline Grinding fluid & $\begin{array}{l}\text { Soluble type (JIS W-2-2) } \\
2 \% \text { dilution }\end{array}$ \\
\hline Workpiece & $\begin{array}{l}\text { High speed tool steel (JIS SKH51) } \\
\text { Hardness: HRC65 } \\
\text { Dimensions: } 100^{l} \times 5^{t} \times 30^{h} \mathrm{~mm}\end{array}$ \\
\hline
\end{tabular}

to observe directly the wheel surface using a scanning electron microscope with multi-probe (multi-probe SEM). Representative monocrystalline $\mathrm{cBN}$ grit has been used for $\mathrm{cBN}$ wheel. Grinding experiments have been carried out with surface plunge grinding method on a horizontal spindle surface grinding machine. The experimental conditions are listed in Table 1. Workpiece material was high speed tool steel (JIS SKH51). Grinding force components were measured using a piezoelectric dynamometer (Kistler/9257B). The dressing of cBN wheel has been performed by using a rotary diamond dresser equipped with an AE sensor (Dressing wheel: SD40Q75M) under the following dressing conditions of: peripheral speed ratio 0.5 , dressing speed $30 \mathrm{~m} / \mathrm{s}$, dressing lead $0.1 \mathrm{~mm} / \mathrm{rev}$, dresser depth of cut $2 \mu \mathrm{m} \times 5$ times.

\section{Experimental Results and Discussion}

\subsection{Grinding characteristics of $\mathrm{cBN}$ wheel in the grinding process}

Before characterizing the wheel surface topography, we have evaluated the change of grinding performance of $\mathrm{cBN}$ wheel in the grinding process. Figure 2 shows the changes of grinding forces $F_{t}^{\prime}, F_{n}^{\prime}$, wheel wear $\Delta R$ and surface roughness $R a$ with increasing stock removal $V_{w}^{\prime}$. On the bases of the changes in these characteristic parameters, the grinding process may be divided into the following two regions:

(1) Initial wear region over stock removal range from 0 to $1000 \mathrm{~mm}^{3} / \mathrm{mm}$, in which a rapid decrease of grinding force and a rapid increase of wheel wear occur with increasing stock removal

(2) Steady-state wear region over stock removal range larger than $1000 \mathrm{~mm}^{3} / \mathrm{mm}$, in which the wheel wear rate maintains a nearly constant value. However, grinding forces increase gradually in stock removal range from 1000 to $6000 \mathrm{~mm}^{3} / \mathrm{mm}$ and then maintain a nearly constant value in stock removal range larger than $6000 \mathrm{~mm}^{3} / \mathrm{mm}$. Therefore, this steady-state wear region may be divided in more detail into the following two regions:

1 ) Steady-state wear region (a) in stock removal range from 1000 to $6000 \mathrm{~mm}^{3} / \mathrm{mm}$

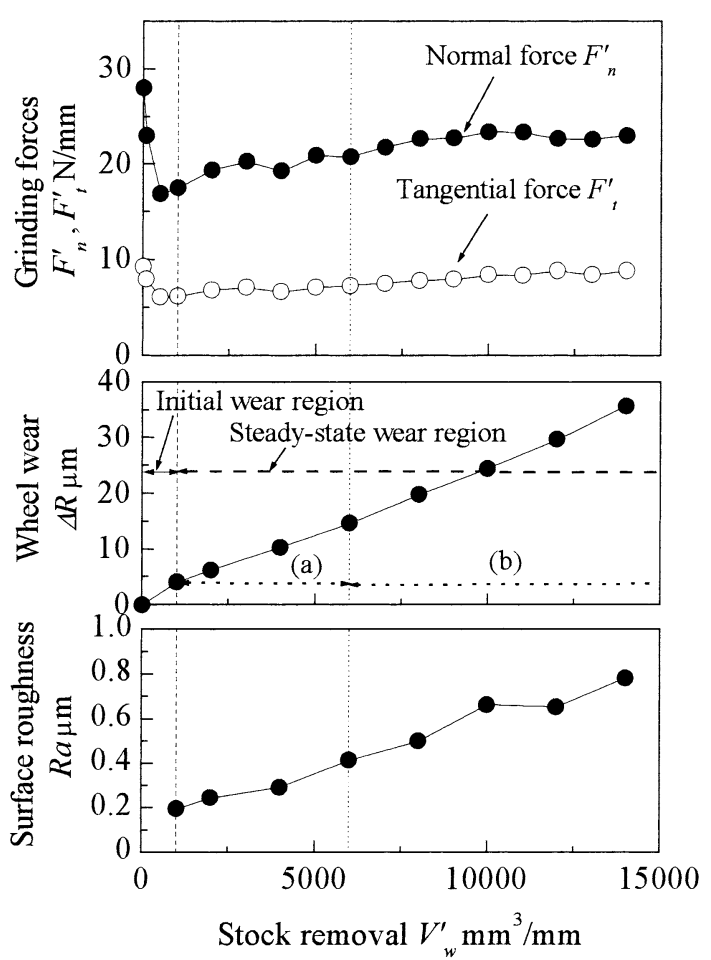

Fig. 2 Changes of grinding characteristic parameters in grinding process

2 ) Steady-state wear region (b) in stock removal range larger than $6000 \mathrm{~mm}^{3} / \mathrm{mm}$.

\subsection{Topographic features of wheel surface in the grinding process}

In order to grasp the topographic features of wheel surface during the grinding process, the changes of wheel surface with increasing stock removal have been observed using multi-probe SEM. Figure 3 shows sequential SEM images, sequential 3-dimensional profiles, and sequential contour maps that were observed at an area of $2.4 \mathrm{~mm} \times$ $1.8 \mathrm{~mm}$ on the wheel surface with a progress of grinding. From these results, we confirm that the distribution of cutting edges becomes coarser successively with stock removal because the fracture of cutting edge and the releasing of grit occur intermittently. The radial distance into the wheel from the outermost protruding cutting point is denoted by a radial depth $z$. The cumulative number of cutting points per unit area that exit to the radial depth of $z \mu \mathrm{m}$, that is, the cutting edge density $C_{s} \mathrm{~mm}^{-2}$, was calculated on the basis of the computer analysis using the 3 dimentional profiles as shown in Fig. 3. From the change of cutting edge density $C_{s}$, the feature of wheel surface was quantitatively estimated. The relationship between cutting edge density $C_{s}$ and radial depth $Z$ is shown in Fig. 4. Also, the relationship between cutting edge density $C_{s}$ and stock removal $V_{w}^{\prime}$ is shown in Fig. 5. From these results, it is grasped that cutting edge density $C_{s}$ decreases with increasing stock removal. Such decrease of cutting edge density is mainly caused by the fracture or releasing 
Grinding direction

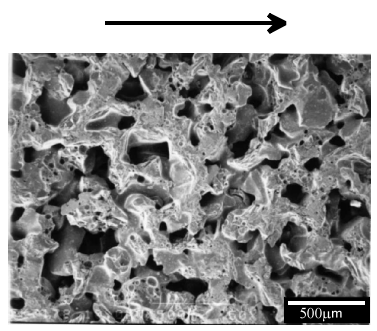

Grinding direction

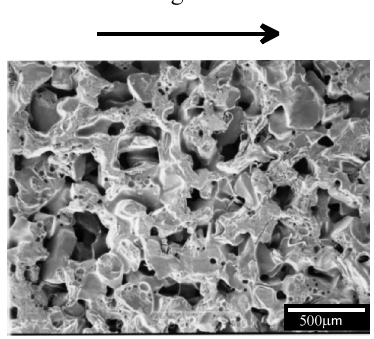

Grinding direction

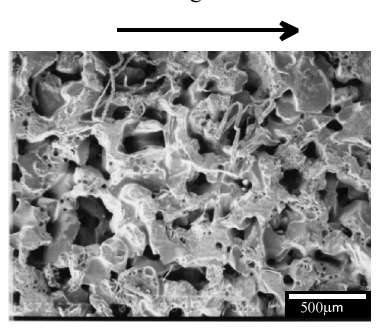

Grinding direction

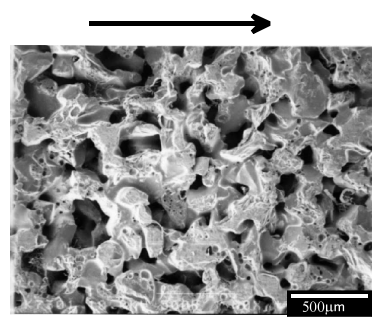

Grinding direction

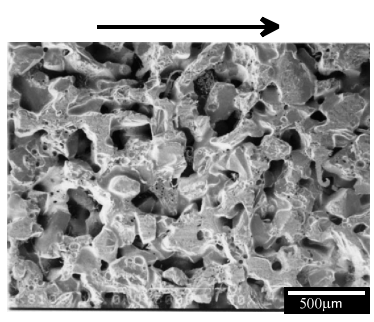

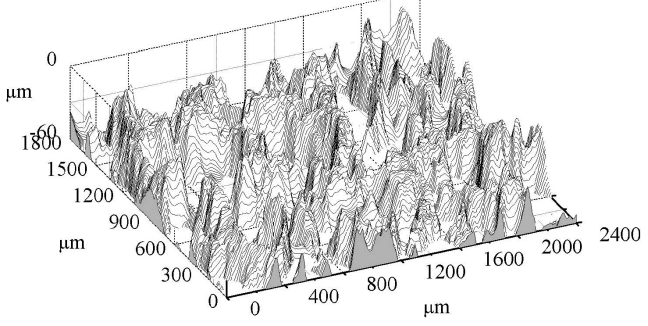

(a) $V_{w}^{\prime}=0 \mathrm{~mm}^{3} / \mathrm{mm}$

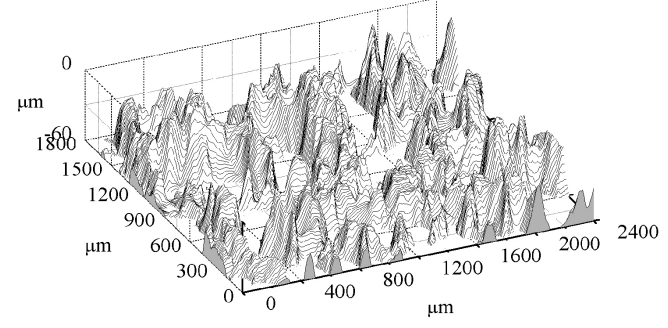

(b) $\quad V_{w}^{\prime}=2000 \mathrm{~mm}^{3} / \mathrm{mm}$

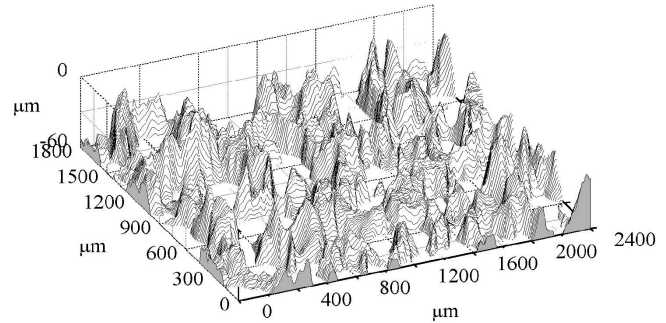

(c) $V_{w}^{\prime}=6000 \mathrm{~mm}^{3} / \mathrm{mm}$

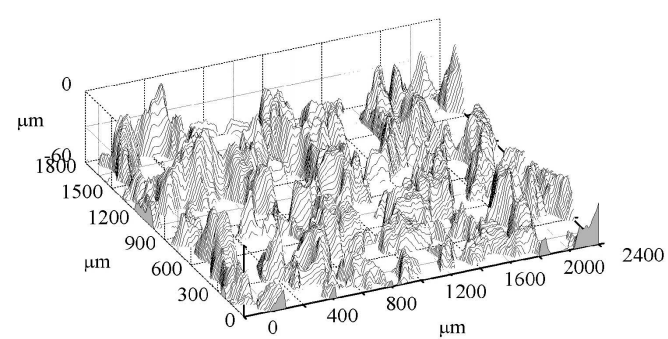

(d) $\quad V_{w}^{\prime}=10000 \mathrm{~mm}^{3} / \mathrm{mm}$
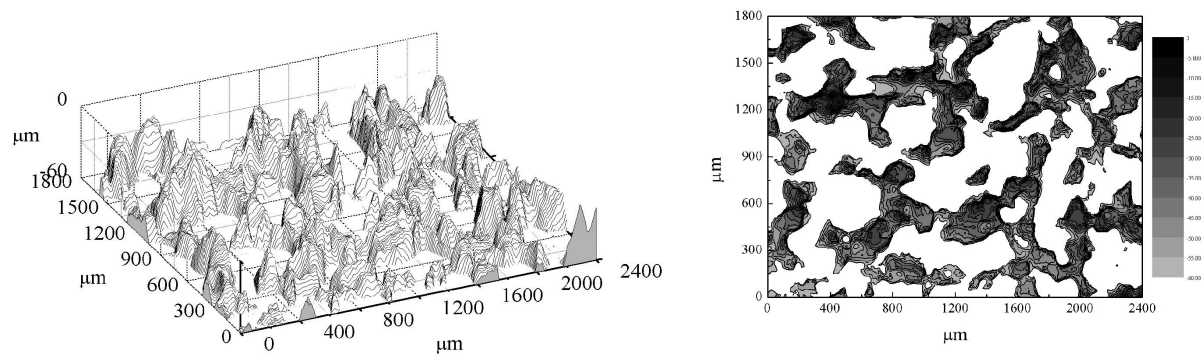

(e) $V_{w}^{\prime}=14000 \mathrm{~mm}^{3} / \mathrm{mm}$
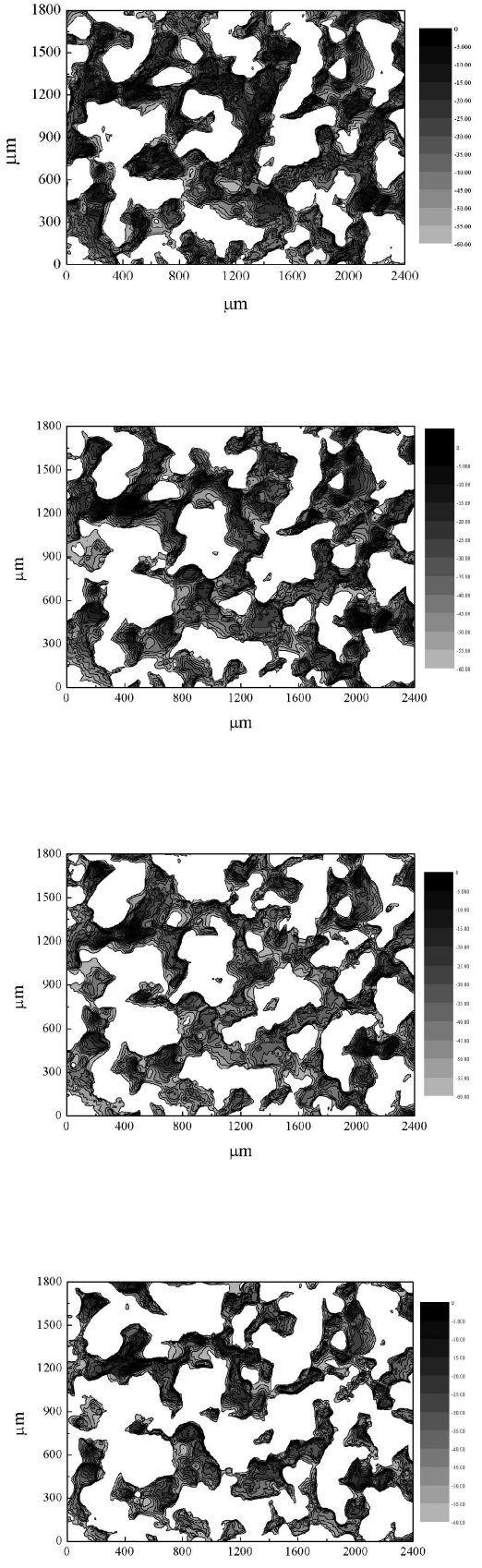

Fig. 3 Change of $\mathrm{cBN}$ wheel surface in grinding process (SEM images, 3-dimensional profiles and contour maps) 


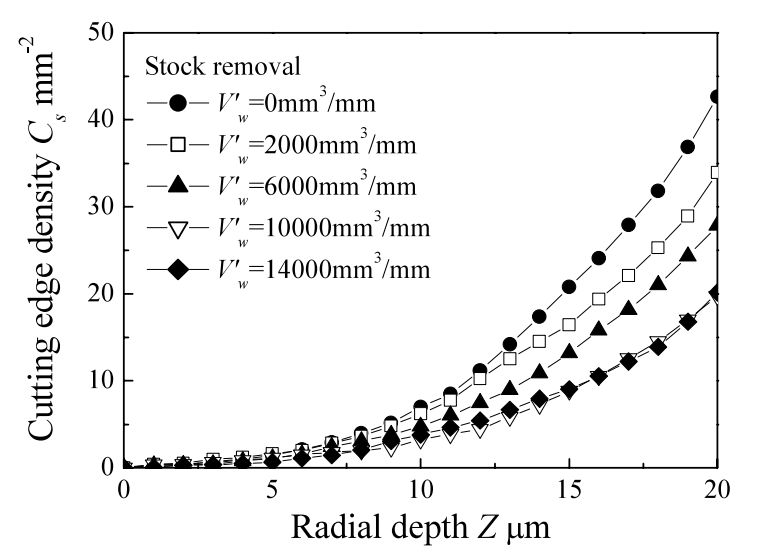

Fig. 4 Relationship between cutting edge density and radial depth

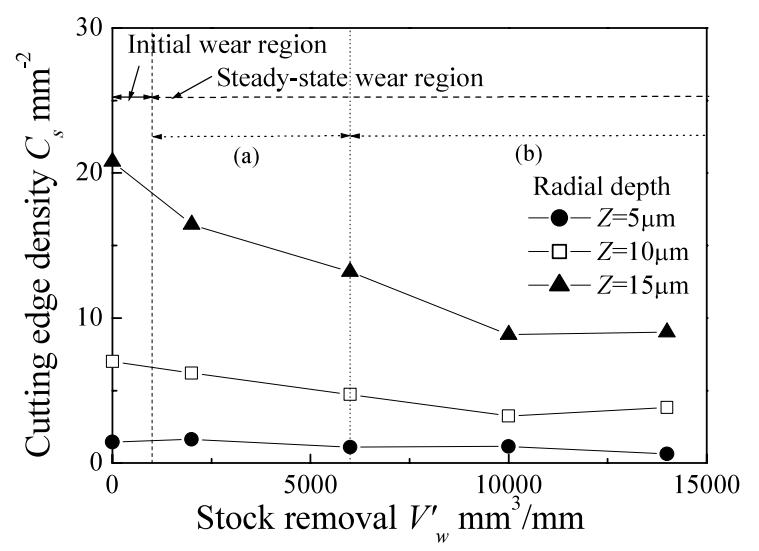

Fig. 5 Change of cutting edge density with increasing stock removal

of the abrasive grits as described above.

The trend in decreasing of $C_{s}$ with stock removal is closely concerned with the change in roughness of the ground surface with stock removal shown in Fig. 2. That is, it seems that the increase in roughness of ground surface in the grinding process is mainly due to the reduction of cutting edge density caused by the fracture of cutting edges and the releasing of grit during grinding.

\subsection{Microstructure of grain cutting edges}

The changes of SEM images and 3-dimensional profiles of typical grain cutting edge with increasing stock removal are shown in Fig. 6. In the initial wear region over stock removal range from 0 to $1000 \mathrm{~mm}^{3} / \mathrm{mm}$, a part of $\mathrm{cBN}$ grain and bond fracture, and these shapes change greatly. In other words, a part of grain cutting edges that were unstable after dressing is fractured and consequently new sharp cutting edges are formed. For these reason, rapid decrease of grinding force and rapid increase of wheel wear occur in this initial wear region. The micro fractures are considerably contained in these fractures of $\mathrm{cBN}$ grits.

In the steady-state wear region (a) over stock removal range from 1000 to $6000 \mathrm{~mm}^{3} / \mathrm{mm}$, attrition wear is caused in a part of cutting edge surface. Grinding forces increase gradually because this attrition wear develops slowly with stock removal. Afterwards, a large fracture is observed in front of cutting edge. In the steadystate wear region over stock removal range larger than $1000 \mathrm{~mm}^{3} / \mathrm{mm}$, the tip of cutting edge generally looks like a flat surface. Especially, as some wear streaks are observed on the cutting edge surface at $V_{w}^{\prime}=6000 \mathrm{~mm}^{3} / \mathrm{mm}$, its surface looks like a flat ductile surface. However, when it is observed with a high magnification, we can find a large number of micro unevennesses on the cutting edge surface.

Such micro unevenness is also observed on the cutting edge surface in the steady-state wear region (b) over the stock removal range larger than $6000 \mathrm{~mm}^{3} / \mathrm{mm}$. Generally, the micro unevenness has a brittle shape with sharp edges. A typical example of the micro unevenness is shown in Fig. 7. The size of concavities and projections that form the micro unevenness is about $5 \mu \mathrm{m}$ in grinding direction, about $10 \mu \mathrm{m}$ in perpendicular to grinding direction and about $4 \mu \mathrm{m}$ in radial depth. Moreover, these concavities and projections have an incisive shape. These results show that the micro unevenness is generated by brittle micro fracture. At the same time, the surface profile of this micro unevenness changes with increasing stock removal. Therefore, this generation of the micro unevenness is a kind of self-sharpening phenomenon due to the micro fracture. We will call this 'micro self-sharpening' or 'micro self-dressing'. Owing to this phenomenon, grinding forces can maintain a nearly constant value in this steadystate wear region (b).

\subsection{Fractal analysis of wheel surface profile}

In order to characterize the feature of wheel surface, it is necessarily to estimate very complicated shapes of the grain cutting edges quantitatively. We have tried to evaluate the intricate shapes of grain cutting edges quantitatively using fractal dimension. Fractal dimension is a quantitative value that can express a complication of objects. In popular language, a point is zero-dimension. A line is one-dimension. A flat surface is two-dimension. And then, fractal dimension is developed through those. For example, fractal dimension of a line is 1 and fractal dimension of the coastline is 1.3. Therefore, higher fractal dimension expresses more complicated shape. In the wear of abrasive grains, when attrition wear or large fracture on the grain cutting edge generate, fractal dimension of the cutting edge surface decreases because it is composed of long lines. On the other hand, when micro fracture occurs on the cutting edge, fractal dimension of the cutting edge surface increases because it is composed of short lines ${ }^{(4),(5)}$. Thus characteristics of cutting edge wear may be quantitatively estimated with this method.

There are several methods for calculating fractal dimension. In this study, we have used the mesh count- 
Grinding direction
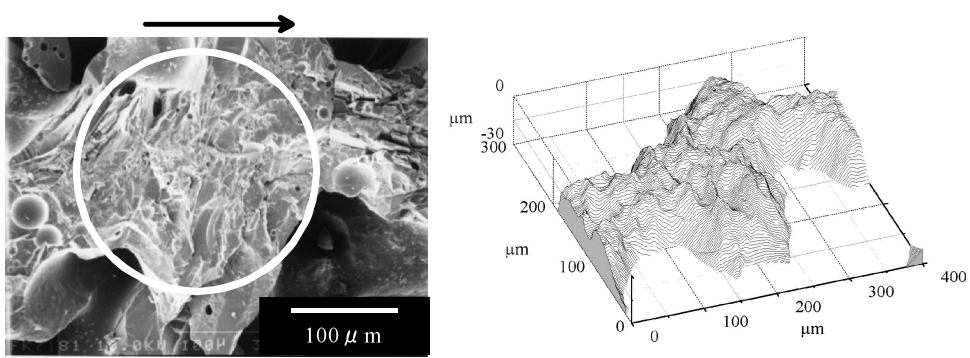

(a) $V_{w}^{\prime}=0 \mathrm{~mm}^{3} / \mathrm{mm}$

Grinding direction
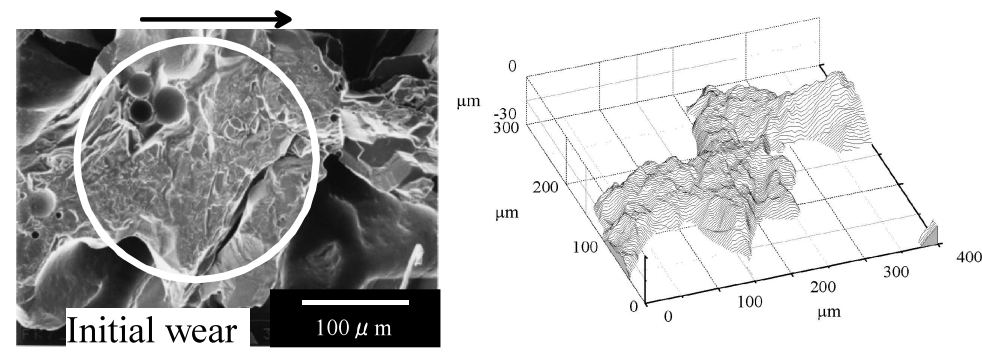

(b) $\quad V_{w}^{\prime}=2000 \mathrm{~mm}^{3} / \mathrm{mm}$

Grinding direction
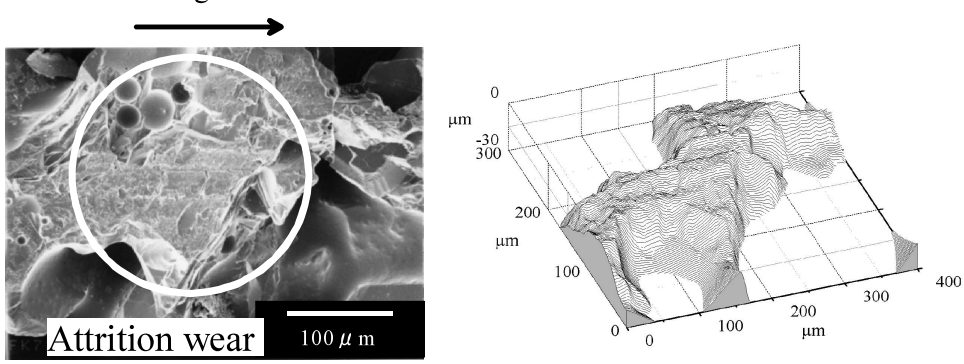

(c) $V_{w}^{\prime}=6000 \mathrm{~mm}^{3} / \mathrm{mm}$

Grinding direction
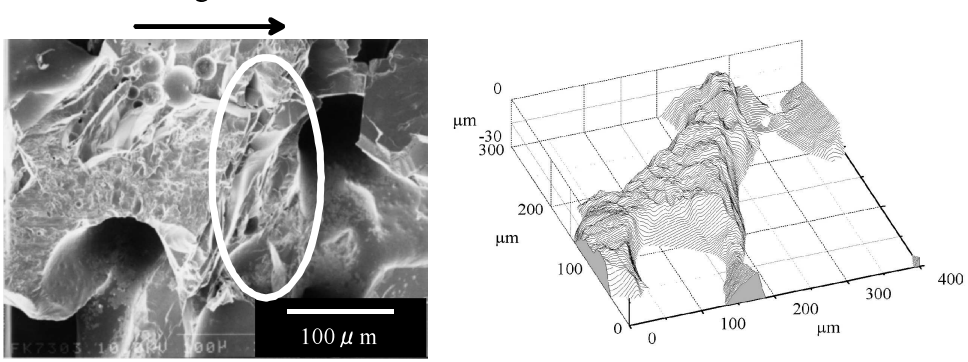

(d) $\quad V_{w}^{\prime}=10000 \mathrm{~mm}^{3} / \mathrm{mm}$
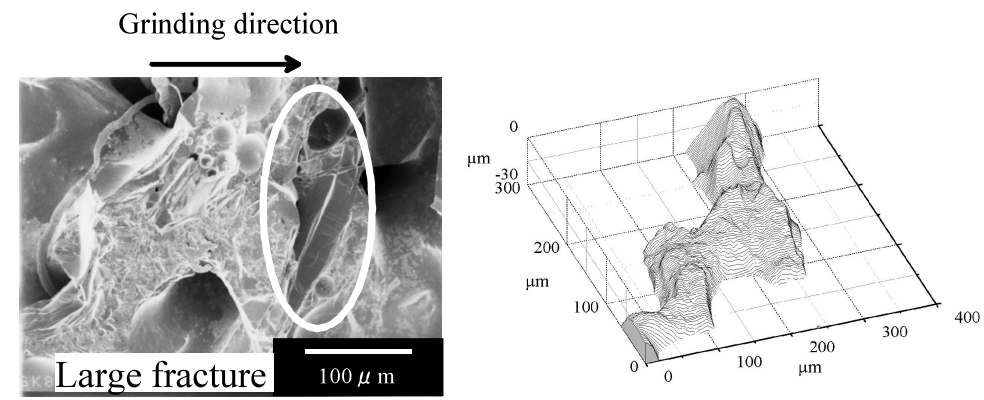

(e) $V_{w}^{\prime}=14000 \mathrm{~mm}^{3} / \mathrm{mm}$

Fig. 6 Change of cBN grain cutting edge in grinding process (SEM images and 3-dimensional profiles) 

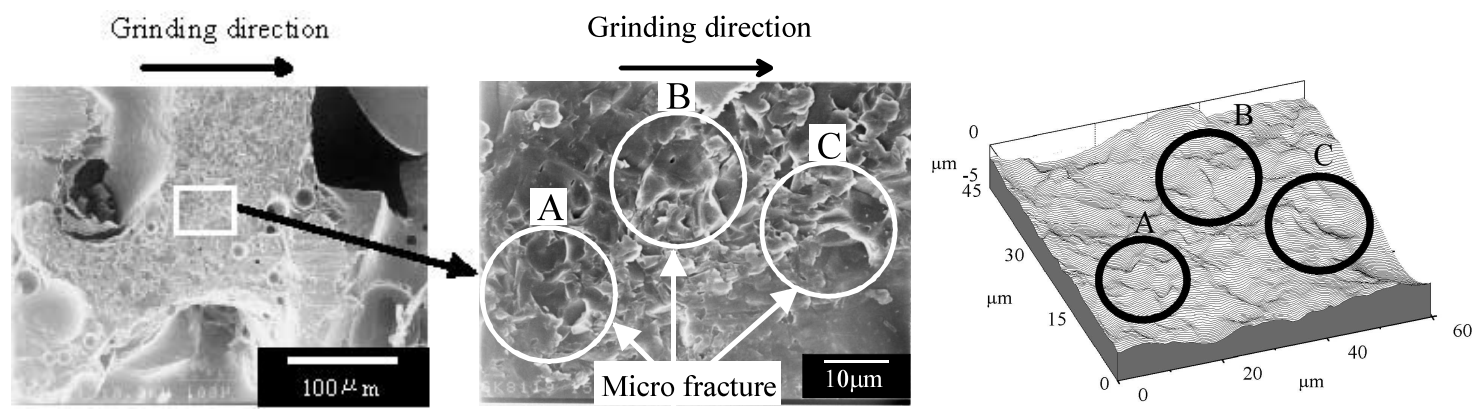

(a) $V_{w}^{\prime}=14000 \mathrm{~mm}^{3} / \mathrm{mm}$
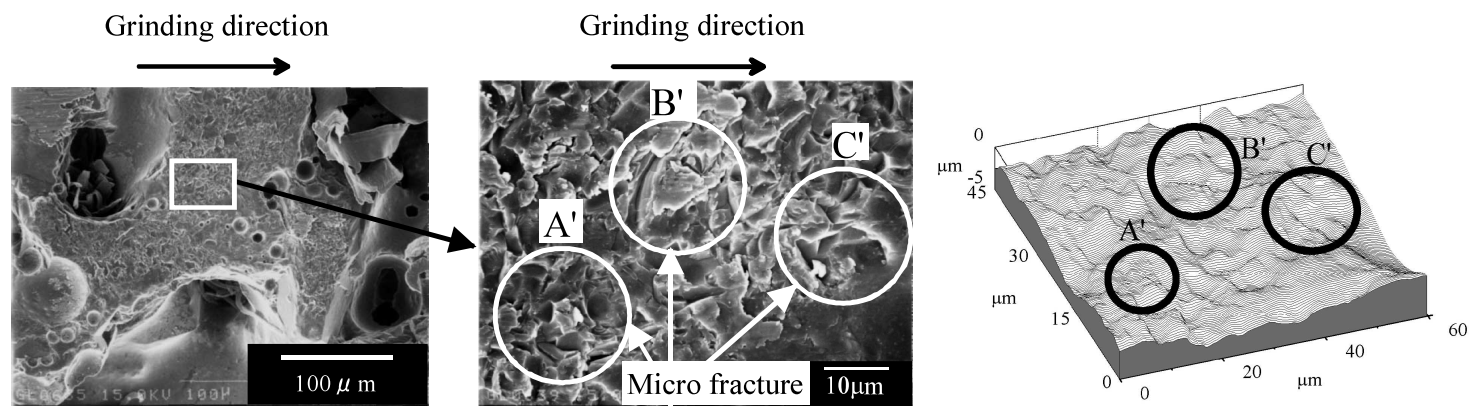

(b) $V_{w}^{\prime}=14500 \mathrm{~mm}^{3} / \mathrm{mm}$

Fig. 7 Micro self-sharpening phenomenon owing to micro fracture of cutting edge (SEM images, high magnification SEM images and 3-dimensional profiles)
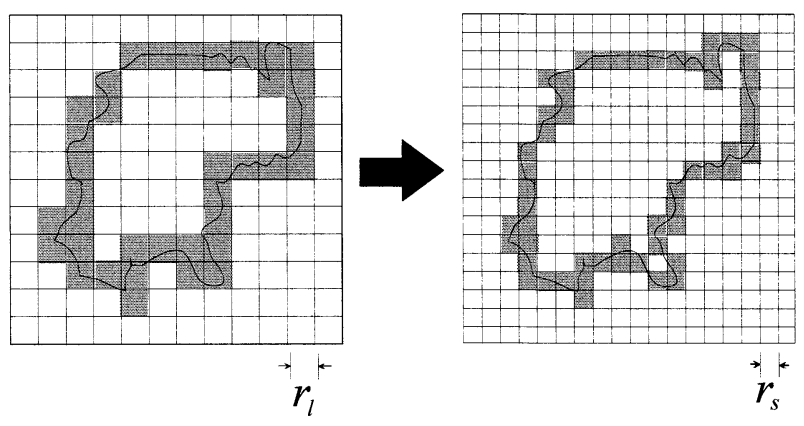

Fig. 8 Fractal analysis using mesh counting method $\left(r_{l}>r_{s}\right)$

ing method because of its simple computer processing and high calculation accuracy. Figure 8 shows an illustration of fractal analysis using mesh counting method. Sampled profile line is divided by square grid with mesh size of $r$. And then, the number of boxes intersected with profile line $N(r)$ is counted. When mesh size $r$ is scaled down, the relationship between $N(r), r$ and fractal dimension $D$ is given by

$$
N(r) \propto r^{-D}
$$

On the bases of this equation, $r$ is taken on horizontal $\log$ axis, and $N(r)$ is taken on vertical $\log$ axis. When data points are on a straight line in $\log N(r)-\log r$ plot, fractal dimension $D$ is given by a slope of the straight line, that is, its value is calculated by following equation.

$$
D=-\frac{d(\log N(r))}{d(\log r)}
$$

In this study, fractal dimension was calculated in area of $1.1 \times 0.8 \mathrm{~mm}^{2}$. Typical examples of contour map of the wheel surface and examples of $\log N(r)-\log r$ plot are shown in Fig. 9. Fractal dimension was obtained as average values of results calculated in some areas selected randomly. Results of fractal analysis at radial depths $Z=10$ and $20 \mu \mathrm{m}$ are shown in Fig. 10.

As shown in Fig. 10 (b), there is no significant difference in fractal dimension at radial depth $Z=20 \mu \mathrm{m}$ in the grinding process because the grain cutting edges to this radial depth don't relate to the grinding action. However, there is a significant difference in fractal dimension at radial depth $Z=10 \mu \mathrm{m}$ in the grinding process.

Fractal dimension $D$ increases in initial wear region over stock removal range from 0 to $1000 \mathrm{~mm}^{3} / \mathrm{mm}$, because a part of grain cutting edges that is unstable after dressing is fractured and consequently many sharp cutting edges are formed.

Next, fractal dimension $D$ decreases gradually with stock removal in steady-state wear region (a) over stock removal range from 1000 to $6000 \mathrm{~mm}^{3} / \mathrm{mm}$, because attrition wear is caused on a part of cutting edge surface. Grinding forces increase gradually and fractal dimension decreases gradually because this attrition wear develops slowly with stock removal.

Moreover, in steady-state wear region (b) over stock removal range larger than $6000 \mathrm{~mm}^{3} / \mathrm{mm}$, fractal dimension $D$ maintains a nearly constant value, because abovedescribed micro self-sharpening phenomenon owing to micro fracture occurs and consequently wheel surface 

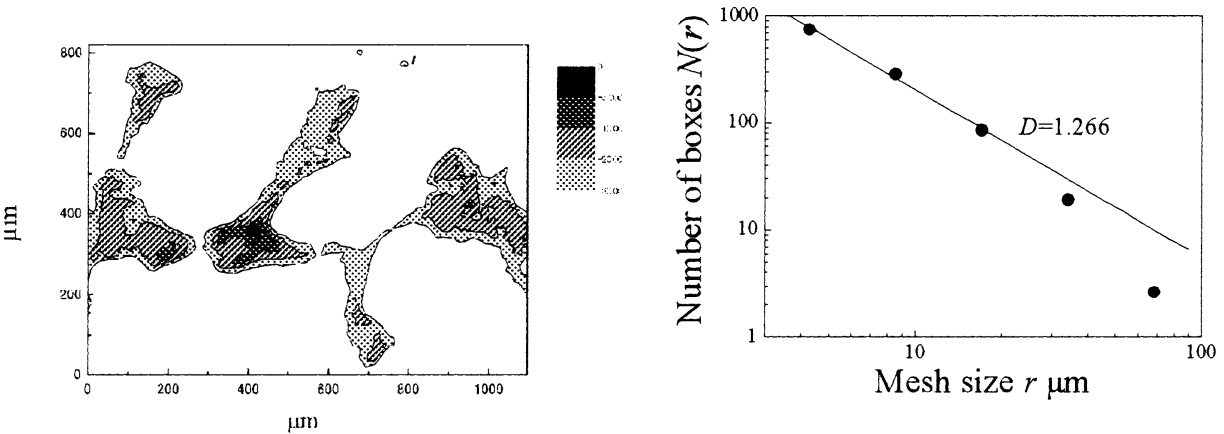

(a) $V_{w}^{\prime}=0 \mathrm{~mm}^{3} / \mathrm{mm}$
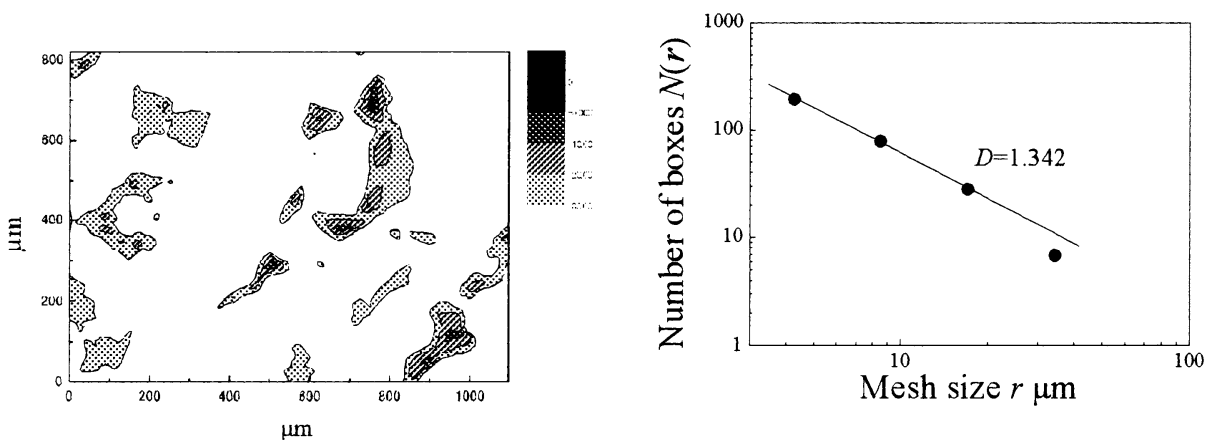

(b) $V_{w}^{\prime}=2000 \mathrm{~mm}^{3} / \mathrm{mm}$
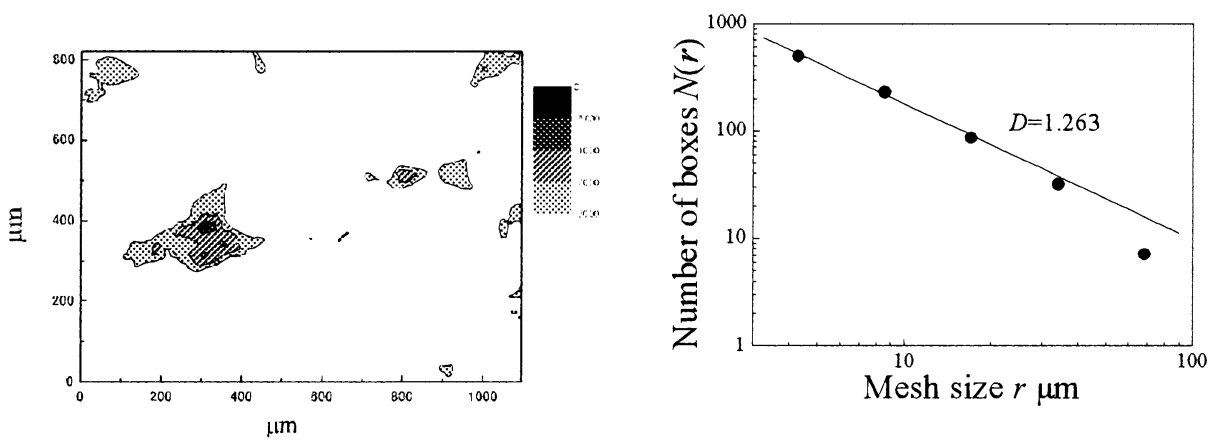

(c) $V_{w}^{\prime}=14000 \mathrm{~mm}^{3} / \mathrm{mm}$

Fig. 9 Contour map of wheel surface and $\log N(r)-\log r$ plot

maintains a nearly constant condition in this region.

Thus, the change in fractal dimension $D$ of the wheel surface profile in the grinding process is closely related to the change of grinding force dominated by wear behavior of the grain cutting edges.

\section{Conclusions}

The changes of the wheel surface topography in the grinding process with vitrified $\mathrm{cBN}$ wheels have been investigated on the basis of 3-dimensional analysis using a multi-probe SEM. Moreover, the change of the wheel surface profile in the grinding process has been evaluated using fractal analysis. The main results obtained in this study are summarized as follows.

(1) There are two regions: an initial wear region and a steady-state wear region, in the grinding process.

(2) In the initial wear region, a rapid decrease of grinding force and a rapid increase of wheel wear occur with increasing stock removal.

(3) In the steady-state wear region, the micro selfsharpening phenomenon owing to a micro fracture as well as the attrition wear of the cutting edge occurs.

(4) The change in fractal dimension of the wheel surface profile in the grinding process is closely related to the change of grinding force dominated by wear behavior of the grain cutting edges.

\section{References}

( 1 ) Ichida, Y., Fredj, N.B. and Usui, N., The Micro Fracture Wear of Cutting Edges in CBN Grinding, The 2nd Int. Abrasive Technology Conf., (1995), pp.501-504.

(2) Ichida, Y. and Kishi, K., The Development of Nanocrystalline CBN for Enhanced Superalloy Grinding Performance, ASME J. of Manuf. Sci. Eng., Vol.119, No.1 (1997), pp.110-117.

( 3 ) Cai, R. and Rowe, W.B., Assessment of Vitrified CBN Wheels for Precision Grinding, Int. J. Mach. Tools 


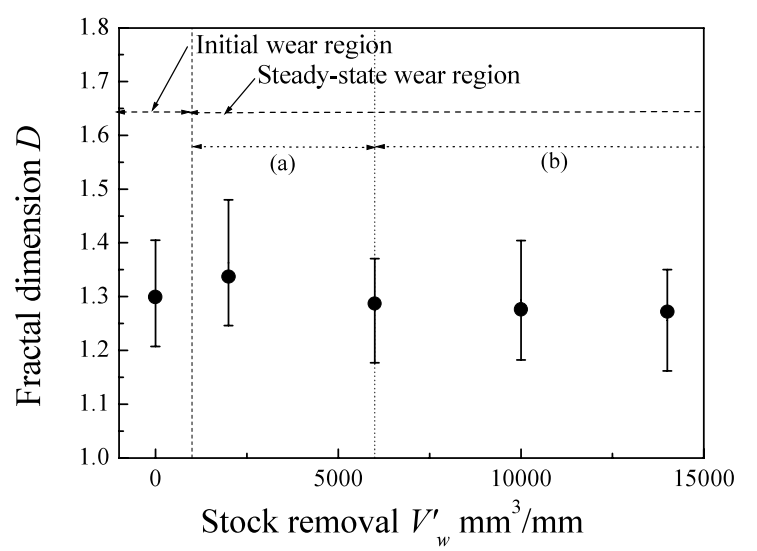

(a) Radial depth $Z=10 \mu \mathrm{m}$

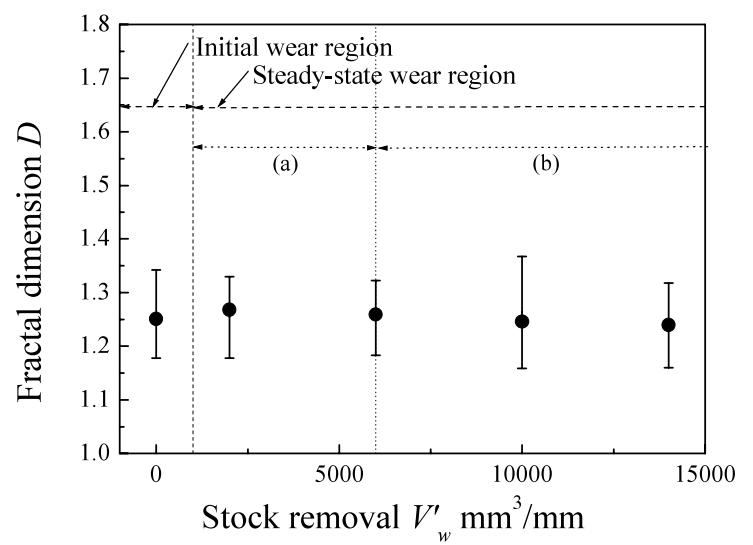

(b) Radial depth $Z=20 \mu \mathrm{m}$

Fig. 10 Change of fractal dimension with increasing stock removal
Manuf., Vol.44 (2004), pp.1391-1402.

(4) Hagiwara, S., Obikawa, T. and Yanai, H., Evaluation of Lapping Grains Based on Shape Characteristics, J. Jpn. Soc. Prec. Eng., (in Japanese), Vol.61, No.12 (1995), pp.1760-1764.

( 5 ) Zhang, Y., Luo, Y., Wang, J.F. and Li, Z., Research on the Fractal of Surface Topography of Grinding, Int. J. Mach. Tools Manuf., Vol.41 (2001), pp.2045-2053. 